concept of "primary" and "secondary" segments which cannot now be accepted should occupy such important cornors in Beklemishev's argument. He therefore uses terms such as "kinetoblast" and "phagocytoblast".

Yet there is much to be gained from a reading of these volumes. The comparative approach to the muscular systems, circulatory systems, reproductive organs and to the development of the colonial habit in diverse phyla is stimulating in the detail in which each comparison is made.

This is a book which every zoology department should have in its library. It is a mine of information, much of which is not readily available except in specialist texts or papers. It is well printed and produced, and the publishers are to be congratulated on making this work available in English.

R. P. Dalks

'Tiegs, O. W., and Manton, S. M., Biol. Rev., 33, 255 (1958).

2 Anderson, D. T... Acta Zool., 47, 1 (1966).

${ }^{3} \AA$ kesson, B., Ark. Zool., 20, 55 (1967).

\section{STUMPTAIL BEHAVIOUR}

The Behavioral Repertoire of the Stumptail Macaque A Descriptive and Comparative Study. By Mireille Bertrand. (Bibliotheca Primatologica, No. 11.) Pp. $\mathrm{xi}+273$. (Karger: 13asel and New York, 1969.) 122s; $\$ 14.65$.

This monograph describes in detail the behavioural repertoire of Macaca speciosa. Most of the information was obtained from observations of captive animalsusually ones living in groups in large eages. A brief field study allowed a few comparisons to be made with the behaviour of wild animals, and in some cases comparisons are made with the behaviour of other primate species.

The first two chapters deal with the taxonomy and distribution of stumptails, and with the materials and methods used in the study. The next chapter presents quantitative data on the proportion of time spent in various occupations (for example, feeding, grooming, locomotion) by the groups of eaptive animals. The group structure was manipulated so that the bchaviour of non-adults alone could be compared with that of nonadults in the presence of adults and vice versa. Not surprisingly there were differences, and furthermore a few observations on a wild group suggested that they differed from the captive ones.

The following seven chapters each contain detailed descriptions of different types of behaviour. It is unfortunate that the criteria for the assignment of patterns or groups of patterns between these chapters are not consistent. For instance, play is assigned as follows: locomotory play is with locomotion because some of the same motor patterns are involved (a descriptive criterion); rough-and-tumble play is with agonistic and friendly behaviour because of its comparability with agonistic behaviour and because of a similarity in function in establishing dominance (descriptive and functional eriteria); investigatory play is with watchful and alarm behaviour because they are elicited by the same kinds of environmental stimuli (a causal critcrion). The behavioural category "play" is undoubtedly too broad to be specially useful, particularly when function is being considered, but the subdivision of this or any other such category on variable criteria is no more than a hindrance.

The observations are, however, of high quality, and the details of the postures, facial expressions and vocalizations, and of the contexts in which they occur, provide a solid basis for comparison with other species. Furthermore, anybody who has the opportunity to study the species in the wild will be much helped by the descriptions in the book. The descriptions are well supported by good photographs, including sound spectrographs, and line drawings. Thero is a good bibliography but, unfortunately, no index.

\section{Obituaries}

\author{
Earl Russell
}

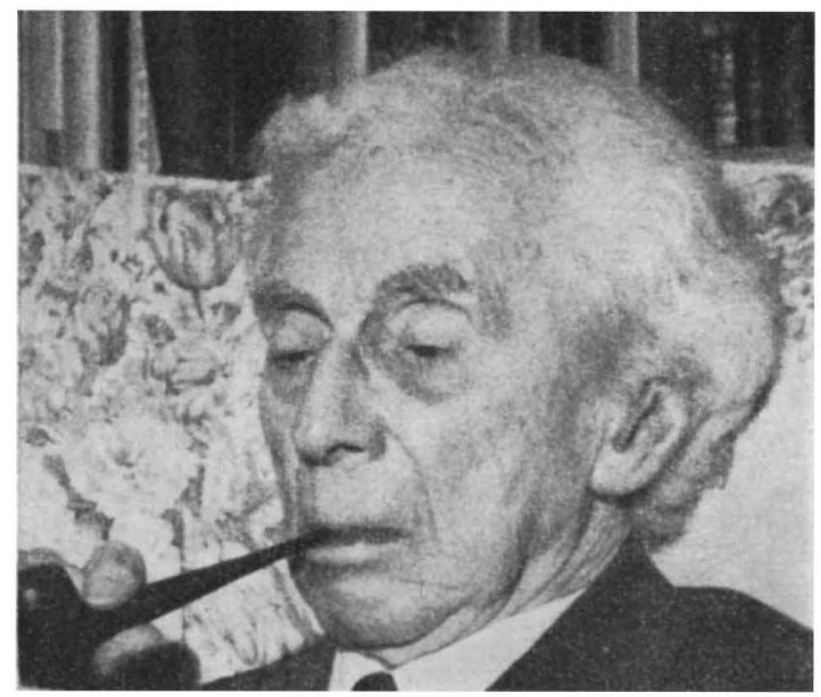

EARL Russell, OM, FRiS, died on February 3, 1970, at the age of 97 . As a philosopher in the widest and oldest sense of the word, he had the rare ability to communicate lucidly with Iayman and professional philosophor alike, and to extend the range of his interests consistently from symbolic logic to social involvoment. His intellectual scope included politics, the history of philosophy, mathematics and, not least, science.

Bertrand Russell's philosophy of science was very much a product of his wider philosophical and logical interests. After his pre-1900 abandonment of idealism, Russell became a logical realist and a pluralist. His analysis of science was dominated by two powerful maxims. The first was a determination to pursue a robustly realistic "common sense" attitude to those objects, both concrete and abstract, with which science deals. The "real" things in the world were not inextricably mental-the pervading orthodox view--but independent, individual things whose discovery and description required an analysis of human belief in order to find their correct form. These forms were to be expressed in simple or "atomic" propositions.

Pursuing this analysis in The Principles of Mathematics (1903) Russell was to find an overabundance of "real" things: "A man, a moment, a number, a class, a relation, a chimaera or anything else that can be mentioned"such an excess constituted a challenge to an orderly and disciplined mind. Nevertheless, his pursuit of this analysis placed and kept him firmly in the British empirieist tradition.

In the writing of his magnum opus, the celebrated Principia Mathematica, Russell developed the tochniques of "logical construction" of one entity from another which were to support his second maxim: "Whenever possible, substitute constructions out of known entities for inferences to unknown entities". Numbers become classes of classes of objects and later, in The Analysis of Matter (1927), objects became classes of events, which were constructed from classes of sense impressions.

Although a good deal of Russell's analysis of the content and validity of our knowledge of the world is conducted at an abstract level (as, for example, in Our Knowledge of the External World, 1914) he did not hesitate to plunge where necessary into a detailed analysis of current scientific theories. An example of this was The Analysis of Matter, 